\title{
The Social "Cost" of Working in Groups and Impact on Values and Creativity
}

\author{
Mark A. Runco \\ University of Georgia, Athens, GA USA \\ E-mail address: runco@uga.edu

\section{Selcuk Acar} \\ Buffalo State, State University of New York, USA \\ E-mail address: acars@buffalostate.edu

\section{Mengying Tang} \\ East China Normal University, Shanghai, China \\ E-mail address: mengrenmengren@163.com
}

\author{
Ning Hao \\ East China Normal University, Shanghai, China \\ E-mail address: nhao@psy.ecnu.edu.cn \\ Jing Yang \\ East China Normal University, Shanghai, China \\ E-mail address: yangjing199101@126.com
}

\section{ARTICLE INFO}

\section{Keywords:}

Psychoeconomics

Costs

Originality

Divergent Thinking

Values

\section{Article history:}

Received: 8 March 2016

Received in revised form: 30 July 2016

Accepted: 8 October 2016

ISSN: 2354-0036

DOI: 10.1515/ctra-2016-0015

\section{A B S T R A C T}

Creative things are always original, but they must be more than just original. They must also have some utility, effectiveness, or value. The present research tested the psychoeconomic definition of "value" and examined how value ratings fluctuated when individuals worked in groups or alone. This psychoeconomic definition of value is very different from that found in previous studies. It was based on ratings obtained after the students participating had been told that their grades depended on their teamwork. Previous studies have used hypothetical ratings of value, but here the ratings were meaningful: there was a contingency placed on making a good decision, and that decision focused on creative teamwork. This investigation also tested the idea that originality and value are both required for creativity. Psychoeconomic theory not only offers an objective and behavioural index of value. It also offers predictions about the "social costs" of working in groups. To test these ideas individuals received two tests of divergent thinking, either while alone (no social cost), working in a small group (low cost), or working in a larger group (high cost). Social preferences were controlled, as was extraversion. Results indicate that fluency did not diminish when the social costs were present. Moreover, originality increased when participants worked in groups. Findings also demonstrated that value judgments can be reliably assessed and that the interaction of value and originality accounted for a significant amount of the variability in creativity ratings. 
Creative ideas, solutions, and products are original. Originality is, however, not a sufficient indicator of creativity. That is because original things may be uncreative. They may be original for good reason - they may be worthless. Thus, creative things are more than just original; they are also effective or valuable. Their value may result from their solving a problem, or it may be that they express an idea effectively. Bruner (1962) described the "effective surprise" of creative things, as did Simonton (2012). Rothenberg and Hausman (1976, p. 7) used the label "pragmatic usefulness," while Runco (1988) pointed to "utility" as the second requirement for creativity, to go along with originality. One way or another, creative things are valuable as well as original. This two-requirement view of creativity has been the "standard definition" for over 50 years (Runco \& Jaeger, 2012).

The value of creative ideas, solutions, and products is surprisingly difficult to determine (Runco \& Charles, 1993). That is because value usually requires a judgment (e.g., "is this an appropriate idea," "does this option solve the problem in a satisfactory manner?") and these can be quite subjective. Values have of course been objectively studied in other contexts, outside of creativity studies. Anderson (1980), for example, described the cognitive algebra used by individuals in several age groups when deciding which cookie they would prefer to have. This line of work is relevant because preferences are expressions of values. Some cookies presented in the research were small, and some were larger, but each was a rectangle. Anderson found that adults valued and preferred cookies that had the largest surface area, and they were clearly using mature and accurate cognitive algebra and recognized, albeit implicitly, that area is most accurately estimated from width $\mathrm{X}$ length. Children, on the other hand, did not use this same implicit procedure and seemed to prefer cookies that appeared to be large based on a simple (and immature) estimate of area (i.e., width added to length). It is quite important that Anderson obtained reliable judgments representing how much individuals would value physical objects.

Value is also inherent in the quality index used in empirical research on citations and scientific achievement (Albert, 1975; Rushton, Murray, \& Paunonen, 1983). These studies look to publications and the like, with two important indicators: one is simply the number of publications, and the other the frequency with which a publication is cited by other professionals. The former is a purely quantitative index, and the latter taken to be an index of the quality of a scientist's work. Higher quality research will be more frequently cited.

These examples show that value can be empirically examined. Still, the values involved in producing and evaluating creative ideas and products have proven to be especially elusive. That no doubt reflects the fact that the value of a creative solution cannot be predicted from existing procedures (algebraic or otherwise). Recall here that creative 
things are always original, so judging the value of creative things may require going beyond existing procedures. The problem of determining the value of creative things is compounded by the fact that the values are sometimes only apparent using a metaphoric variety of logic (Runco, 1996). Simplifying somewhat, creative things may be appealing and useful only if some non-standard logic is applied.

Runco and Charles (1993) attempted to assess value and originality with tests of divergent thinking and an operational definition of value that depended on the appropriateness of an idea for the specific task at hand. Interestingly, they found an inverse relationship between ratings of originality and ratings of appropriateness. This was surprising because it would seem to be contrary to the standard definition of creativity and the requirement of originality and value. Runco and Charles had to use a very simple definition of appropriateness, however. They used divergent thinking tasks, one of which asked participants to list as many square things as they could. This allowed the identification of original ideas, for they were rare or unusual-few people gave them. To assess appropriateness, however, Runco and Charles developed guidelines for judges. An idea was appropriate if it was four sided, and the sides were of equal length, and the object was two-dimensional (not a cube). Thus appropriate things were literally square; and that meant that highly creative things could have been deemed inappropriate because they were not literally fitting. They may have been metaphorically fitting instead. Several others have attempted to empirically study values in the context of creativity (Dollinger, Burke, \& Gump, 2007; Kasof, Chen, Himsel, \& Greenberger, 2007).

One untested but compelling approach to the study of values, as they relate to creativity, can be found in the psychoeconomic theory of creativity (Rubenson \& Runco, 1992). Psychoeconomic theory applies to creativity in a number of ways, including its description of social settings as "markets" for creative behaviour. The best market, be it an organization, school, or community, is one that offers clear benefits and minimizes costs of creative behaviour. Sadly, too often the costs are too high and it is easier (i.e., less costly) to rely on conventional actions and to conform rather than stand out and be original. Costs may take several different forms. They may be social, which would explain why brainstorming was claimed to be ineffective (Rickards \& deCock, 2012). There is, after all, no penalty or cost if you have a bizarre idea but are simply thinking it or writing it down for your own eyes only; but if other people may hear or see the same idea, there is a potential cost. They may laugh at bizarre ideas or simply avoid the person who produced them.

Previous research has reported that groups are often less original and productive than individuals (e.g., McGrath, 1984; Sternberg, 1995), but explanations have focused 
on social loafing (Karau \& Williams, 1993; Sosik, Kahai, \& Avolio, 1998), conformity (Goncalo \& Duguid, 2012; Larey \& Paulus, 1999; Sternberg, 1995), expected evaluations (Dennis \& Gallupe, 1993; Paulus \& Dzindolet, 1993), and "productivity losses" (Diehl \& Stroebe, 1987). Recent research also revealed that there is a bias against creative ideas even though people tend to express that they welcome creativity (Mueller, Melwani, \& Goncalo, 2012). Actually, brainstorming techniques (Osborn, 1957) were developed to overcome such concerns by instructing individuals to defer judgment, strive for quantity, welcome original and wild ideas, and build on other ideas. Although brainstorming techniques have been shown to be effective for groups, compared to groups receiving no instructions (Parnes \& Meadow, 1959), generalizations of findings to originality and flexibility could be questioned.

Fluency, originality, and flexibility might very well be influenced differently by the presence of others during idea generation. One reason to expect such differences can be found in economic reasoning about how personal costs influence behaviour. According to this economic perspective, the presence of others can be a motivating factor for improvements in the quality of ideas but that comes at the expense of decrements in productivity. Knowing that ideas produced are being heard and evaluated by others is likely to put selective pressure on the individuals and is likely to motivate them to produce ideas of higher quality. This heightened concern for quality, however, may reduce productivity. Applying this to the creativity, fluency (productivity) would decrease but originality, an important aspect of idea quality, would increase.

This same psychoeconomic theory also provides an operational definition of "value" that can be assessed in the context of creative problem solving. To understand how psychoeconomic theory defines value, consider the following: If someone is willing to drive 1 mile to obtain an object, but that same person is also willing to drive 10 miles to obtain something else, the second thing is more valuable (to that individual). This of course parallels the more common instance where, if someone is willing to pay $\$ 1$ for something, but willing to pay $\$ 100$ for something else, the latter is more valuable. Note how easily the differences in value can be quantified. That is the beauty of the economic view of value. Certainly the utility of this approach to value is clearest when the values are obtained from actual behaviour. It is one thing to say "I would pay $\$ 10$ for that book," but quite another to observe an individual pull out a wallet and actually pay. The present research placed an actual contingency on the ratings of value. These ratings were not, then, hypothetical but were actually meaningful to the participants. This is described in more detail in the Method. 


\section{OBJECTIVES OF THE PRESENT RESEARCH AND ITS ORIGINAL CONTRIBUTION TO THE CREATIVITY LITERATURE}

The present research was designed to empirically examine the psychoeconomic predictions and assess relationships among value, originality, and creativity. The first objective of this research was to test the position that judgments of value can be quantified. This would be an important contribution to creativity studies. That is in part because judgments of value are too often hypothetical. In the present research participants were led to believe that their judgments would have an impact on an important contingency. Thus the ratings of value were not hypothetical; they were realistic and practically meaningful.

This use of meaningful judgments of value represents an important step towards understanding the creative process, which is the other reason why the method for assessing value examined here is notable. A reliable measure of value will go a long way towards more complete measurement of creativity. Originality can already be objectively determined (Runco, 2013), and if the measure of value developed in the present research is reliable, a more complete picture of creativity will be possible. With this in mind the first objective of the present research was to try the new method for assessing value and to check the reliability of the value judgments.

The second objective of this research was to test a related idea from psychoeconomic theory, namely that individuals will perform like businesses and, when costs and constraints are imposed, they will (a) produce less but (b) what is produced will be of a higher quality. These expectations were examined in this investigation by assessing ideas, the questions translating into, when costs are high, does (a) ideational fluency (a measure of productivity) drop and (b) ideational originality (a measure of quality) increase? It is possible that ideational flexibility will also increase with higher levels of cost, but its tie to "quality" is less certain than that of originality. The examination of flexibility was, then, exploratory. These particular expectations, drawn from macro-economic theory of businesses and applied to individuals, were examined by assigning participants to groups, which varied in terms of the amount of social cost.

The third objective of the present research was to examine the definition of creativity mentioned above, as involving originality and value. As noted above this is the "standard definition" of creativity (for a review see Runco \& Jaeger, 2012), and a reliable measure of value would allow re-examination of the relationships between originality, value, and creativity. 


\section{METHOD}

\section{Participants}

The participants were 91 Chinese undergraduate students enrolled in educational psychology classes. They participated for course credits and were randomly assigned to a High Cost condition ( $n=30$ with 5 persons in each group), a Low Cost condition ( $n=30$ with 3 persons in each group), or a No Cost condition (i.e., work alone, $n=31$ ). One participant in the High Cost condition and two participants in the Low Cost condition were not native Chinese speakers; thus the analyses reported below include only data from the 88 remaining individuals (12 males, 76 females; age: $M=20.09$ years old, SD $=1.25$, Range: 18-23 years old).

\section{Procedure}

The experiment was divided into two phases. In Phase 1, participants' social preference (i.e., preference to work in groups) was measured by means of the Group Preference Scale. This is a 10-item Likert measure with previously demonstrated reliability (Larey \& Paulus, 1999). Openness and Extraversion were measured by NEO-PI-R (Costa \& McCrae, 1992). The NEO-PI-R also has established reliability. It has 240 items, each using a five point Likert scale. After these were completed the participants solved three Uses problems (i.e., newspaper, brick, pencil), and three Similarities problems (i.e., "how is a potato and carrot alike?"; "How is the Earth like the Moon?"; "How is the cat like the mouse?"). The presented sequences of three items were randomly arranged for participants (in the no cost condition) and groups (in the high and low cost conditions). The presented orders of tasks (i.e., Uses and Similarities) were balanced across participants or groups. Participants (or groups) were given a rest (1 min) after finishing each item.

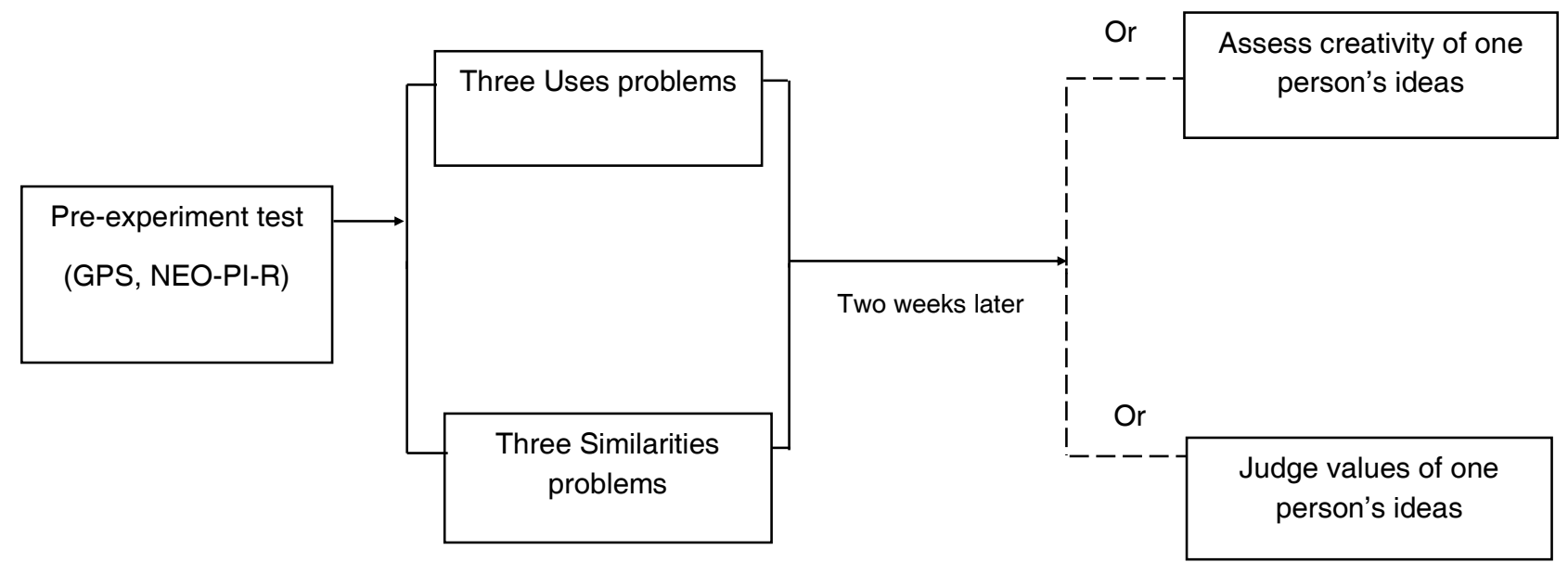


In the higher and lower cost conditions, participants were asked to share their ideas aloud so everyone in their group could hear. Each participant was required to take his or her turn. When it was an individual's turn, he or she was to attempt to solve the problem at hand (Uses or Similarities) and report one idea aloud, without a time limit. Individuals were permitted to skip turns if they had no idea. This continued until the group exhausted all ideas. To add even more social presence, participants' oral responses were recorded by the experimenter using pencil and paper. In the No Cost condition (i.e., work alone), participants orally reported their ideas for the given problems without the limitation of time.

\section{MEASURES}

\section{Value Ratings}

After the data were obtained (in one of the three Cost conditions just described), ratings of value could be calculated. To this end the ideational pools of two DT tasks were constructed for every participant. Ideational pools have shown their utility in several previous studies (Runco \& Mraz, 1992; Runco \& Charles, 1993). The basic idea is that judgments of ideas are likely to be the most accurate if individuals offering the judgments have as much information available as possible. They could judge ideas singly, but they have more information if they see the entire output from any one individual - that is, the ideational pool. Here that led to 176 ideational pools (2 tasks x 88 participants). These pools were anonymous, and when presented (in Phase 2) were done so in a random sequence. They were printed and bound as a handbook so handwriting and other such idiosyncrasies would be eliminated. In Phase 2 (two weeks after Phase 1), the participants returned and were randomly assigned to rate the creativity of these pools ("How creative do you think the ideas of this person are?") or the value of these pools ("how much would you like to work with this person in a problem solving group?"). A Likert scale was used with 1 (not at all) to 5 (very much). That is, there were respectively 44 participants who rated the creativity or judged the values of the pools.

Recall here the idea that there is an important difference between ratings of value that are given in some hypothetical situation and those obtained when something is actually at stake. To ensure that the participants of the present research were serious about their ratings, they were told that their grades depended on how they rated the ideational pools. Here is what they were told:

"Please carefully review the idea pools that your classmates provided, and decide how much you want to work with them (on a scale of 5 points) to solve creative problems. We will arrange the partners for you, based on your decision. And then, you and your partner, as a group, will solve a series of new Uses and Similarities problems. The perfor- 
mance of your group will be graded on creativity; the grade of the group will be the score for everyone in the group. You should know, your score will be included as an important part (20 percent) of your final course score."

These instructions ensured that respondents were serious about their ratings. That is of course critical to the objectives of this research. Those ratings were used to calculate the value data, and if participants had not been told that their grades depended on their ratings, the value ratings would have been hypothetical and perhaps not meaningful. It is one thing to be asked to "pretend that you have a class project and need to work with one other person," which exemplifies a hypothetical situation, and the responses could be very different from those obtained if the person is actually expecting to complete a class project and will be graded on it. Authentic ratings of value must be tied to actual costs, as they were here. Value ratings based on hypothetical situations are not nearly as meaningful. Recall here the examples given in the Introduction, where value was operationalized in terms of actual behavior - driving for 10 miles instead of 1 mile or paying $\$ 100$ instead of $\$ 1$. It is one thing to ask "how much would you be willing to pay" but quite another to count how much money a person has actually paid for something.

Note also that the participants supplying the value ratings believed that their grades depended on their choice of partners, and that they would be graded on creativity. They were asked to use the ideational pools to "choose someone you would like to work with, on your team," the implication being that if they chose the right partners, they would earn a higher grade. This manipulation made it very likely that participants focused on how valuable the ideas were for earning a high grade, when that grade depended on level of creativity. Being explicit that their grade (in their work with partners) depended on creativity also ensured that the value ratings reflected value as a part of creativity and not value more generally (e.g., value as indicative of humour, social appeal, or some other aesthetic quality).

\section{Uses and Similarities Problems}

The Uses and Similarities Problems were also scored for fluency, originality, and flexibility. Fluency scores were indicated by the total number of ideas given per problem (Guilford, 1967; Runco, 1991, 1999). Originality scores were assigned for statistically infrequent responses (Plucker, Runco, \& Lim, 2006; Wallach \& Kogan, 1965). Specifically, the ideas of all participants generated for a given problem were first collected into a comprehensive lexicon. It contained all ideas given and the number of participants who gave each. If a response was statistically infrequent (i.e., if $5 \%$ or less of the participants in the sample gave the response), then it was given a score of "1". All other responses 
(i.e., the common and unoriginal ones) received scores of 0 . Flexibility scores were indicated by the number of categories represented in a respondent's pool of ideas. These categories were chosen a priori, as is the typical method (Guilford, 1968; Runco, 1985). Averages across items were calculated for each participant and each of the fluency, originality, and flexibility indices, for both Uses and Similarities.

\section{RESULTS}

\section{Reliability}

Cronbach's alpha for the value ratings was .96 for Uses and .95 for Similarities. Both indicate good reliability. Alpha for the ratings of creativity was .96 for Uses and .96 for Similarities, again indicating good reliability. The alphas for the three Uses problems were .89 (Fluency), .85 (Originality), and .76 (Flexibility). Alphas for Similarities were .81 (Fluency), .76 (Originality), and .64 (Flexibility).

\section{Analyses of Constraints}

A MANCOVA was computed using Openness, Extraversion, and Social Preference as covariates and comparing the Cost with No-Cost conditions. Results indicated that Extraversion and Social Preference were unrelated to Fluency, Originality, and Flexibility (Fs $(2,82)<1.21$, ns) but Openness was significantly related to the Fluency, Originality, and Flexibility scores $(F s(2,82)=6.31,4.64$, and 6.18 , respectively, $p s=.003, .012$, and .003). Importantly, there were differences between the Cost and No Cost groups after covarying Openness, Extraversion, and Social Preference, but only in the Originality index $\left(F(2,82)=5.82, p=.014, \eta_{\mathrm{p}}{ }^{2}=.124\right)$. Means and SDs are presented in Table 1.

Table 1

\section{Descriptive analyses of divergent thinking items}

\begin{tabular}{llrl}
\hline & & $\boldsymbol{M}$ & $\boldsymbol{S} \boldsymbol{D}$ \\
\hline Uses Fluency & No cost & 10.42 & 5.21 \\
& Cost & 9.05 & 4.78 \\
Similarities Fluency & No cost & 10.34 & 3.73 \\
& Cost & 9.20 & 3.46 \\
Uses Flexibility & No cost & 4.88 & 1.11 \\
& Cost & 4.56 & 1.37 \\
Similarities Flexibility & No cost & 4.92 & 1.14 \\
& Cost & 4.98 & 1.00 \\
Uses Originality & No cost & 4.76 & 3.59 \\
& Cost & 4.82 & 3.28 \\
Similarities Originality & No cost & 3.09 & 2.01 \\
& Cost & 4.68 & 2.41 \\
\hline
\end{tabular}


A second MANCOVA compared the two levels of Cost (groups of 3 persons vs. groups of 5$)$. No differences were statistically significant.

\section{Cost X Personality}

To test the possibility that the impact of Cost depended on one of the three personality traits, a series of regression analyses was computed using fluency, originality, or flexibility as a criteria and Cost X Social Preference, Cost X Extraversion, and Cost X Openness product terms (after main effects) as predictors. They were not significant, indicating that the impact of Cost did not depend on any of the three personality traits. Table 2 presents correlation coefficients among all predictors.

Table 2

\section{Bivariate correlations among different measures of creativity and personality}

\begin{tabular}{|c|c|c|c|c|c|c|c|c|c|c|c|c|}
\hline & 1 & 2 & 3 & 4 & 5 & 6 & 7 & 8 & 9 & 10 & 11 & 12 \\
\hline \multicolumn{13}{|l|}{ 1. Openness } \\
\hline 2. Extraversion & $.45^{\star \star}$ & & & & & & & & & & & \\
\hline 3. Social Preference & .21 & $.52^{\star *}$ & & & & & & & & & & \\
\hline 4. Uses Fluency & $.24^{*}$ & -.10 & -.02 & & & & & & & & & \\
\hline 5. Uses Originality & $.24^{*}$ & -.04 & -.01 & $.95^{\star \star}$ & & & & & & & & \\
\hline 6. Uses Flexibility & $.30^{\star \star}$ & .01 & .01 & $.86^{\star *}$ & $.79^{\star *}$ & & & & & & & \\
\hline 7. Similarities Fluency & $.34^{\star \star}$ & .09 & .12 & $.42^{\star \star}$ & $.36^{\star \star}$ & $.41^{\star \star}$ & & & & & & \\
\hline 8. Similarities Originality & $.23^{*}$ & .16 & .11 & $.36^{\star \star}$ & $.40^{\star *}$ & $.35^{\star *}$ & $.79^{* \star}$ & & & & & \\
\hline 9. Similarities Flexibility & $.28^{\star \star}$ & .06 & .06 & $.34^{\star \star}$ & $.30^{\star *}$ & $.42^{\star \star}$ & $.81^{* \star}$ & $.70^{\star \star}$ & & & & \\
\hline 10. Uses Value & $.29^{\star \star}$ & -.04 & .08 & $.86^{\star \star}$ & $.81^{\star \star}$ & $.79^{\star \star}$ & $.42^{\star \star}$ & $.34^{\star \star}$ & $.40^{\star *}$ & & & \\
\hline 11. Uses Creativity & $.32^{\star \star}$ & -.04 & .08 & $.83^{\star \star}$ & $.83^{\star \star}$ & $.82^{\star \star}$ & $.44^{\star \star}$ & $.43^{\star \star}$ & $.41^{\star \star}$ & $.93^{\star \star}$ & & \\
\hline 12. Similarities Value & $.34^{\star \star}$ & .06 & .12 & $.35^{\star \star}$ & $.28^{\star \star}$ & $.36^{\star \star}$ & $.93^{\star \star}$ & $.79^{\star \star}$ & $.82^{\star \star}$ & $.35^{\star \star}$ & $.39^{* *}$ & \\
\hline 13. Similarities Creativity & $.35^{\star \star}$ & .12 & .15 & $.33^{\star \star}$ & $.31^{\star \star}$ & $.34^{\star *}$ & $.83^{\star \star}$ & $.81^{\star \star}$ & $.82^{\star \star}$ & $.37^{\star \star}$ & $.42^{\star *}$ & $.91^{* *}$ \\
\hline
\end{tabular}

${ }^{* *} p<.01,{ }^{*} p<.05$

\section{Value X Originality for Creativity}

Hierarchical regression analyses were used to address the third objective of this research and to examine the relationship of value with creativity. These analyses used creativity ratings as the criterion and originality ratings, value ratings, and then the interaction (Originality $X$ Value) as predictors. Results indicated that originality explained a significant amount of the variability in the creativity ratings $\left(R^{2}=.71, p<.001\right)$. Value ratings, entered to the regression in a second step, added a significant amount of variance to the equation $\left(R^{2}=.18, p<.001\right)$, as did the Originality $X$ Values interaction 
$\left(R^{2}=.03, p<.001\right)$, which was added to the regression in a third step. This step-by-step regression approach to the testing of interactions was explained by Cohen and Cohen (1975) and has been used many times in the creativity research (e.g., Runco, 1986a, 2013).

Similar analyses were computed for Fluency and Flexibility. Ratings of Fluency and the Fluency $X$ Value interaction explained a significant amount of variability in the creativity ratings. Fluency itself explained a significant amount of the variability in the creativity ratings $\left(R^{2}=.73, \mathrm{p}<.001\right)$. Value ratings, entered to the regression in a second step, added a significant amount of variance to the equation $\left(R^{2}=.14, \mathrm{p}<.001\right)$, as did the Fluency $\mathrm{X}$ Values interaction $\left(R^{2}=.014, \mathrm{p}<.002\right)$, which was added to the regression in a third step.

Much the same was found for Flexibility and the Flexibility $X$ Value interaction: In the first step Flexibility explained a significant amount of the variability in the creativity ratings $\left(R^{2}=.69, \mathrm{p}<.001\right)$. Value ratings, entered to the regression in a second step, added a significant amount of variance to the equation $\left(R^{2}=.18, \mathrm{p}<.001\right)$, as did the Flexibility $\mathrm{X}$ Values interaction $\left(R^{2}=.007, \mathrm{p}<.032\right)$, which was added to the regression in a third step.

\section{DISCUSSION}

The results of this research suggest that value, as a part of creativity assessment, can in fact be reliably assessed. They also support the psychoeconomic prediction that value varies as a function of cost. One prediction was not supported, namely that ideational fluency would decrease when costs were increased. This prediction followed from economic theory and tends to characterize businesses, but apparently it does not apply to individuals and ideas, at least given the design used here. Still, given the salient role of originality in creativity (Runco \& Jaeger, 2012), the finding that originality increased with higher costs is more important. This is consistent with the psychoeconomic theory, which proposes that the quality of ideas will increase when costs increase. Here costs were social and manipulated by asking participants to work in groups, rather than alone. They had to state their ideas out loud, for everyone to hear, and they could see that notes were being taken (by the experimenter) as they shared their ideas.

Also quite important was the result showing that value interacted with originality in predictions of creativity. This finding is directly relevant to the research on creativity and the numerous definitions that creativity is more than just originality and that in some way value must be involved. The present findings also confirm that value can be quantified and manipulated, something too rarely done in studies of creativity. The significant Value $X$ Originality interaction is consistent with the "standard definition" of creativity. The method for obtaining value ratings might be employed widely in future research for a more complete understanding of creativity. Research need no longer rely entirely on originality. Value can also be examined. 
The present findings have practical implications. Although the teamwork demanded by the procedures of the present research were not based on brainstorming (e.g., the particular guidelines of brainstorming were not in the instructions given to the groups), there are implications for understanding brainstorming methods because they also depend on groups and teams. Brainstorming techniques have been criticized because of lower idea production compared to individual idea generation and is used very frequently in organizations that intend to innovate. The method has become even more popular with the internet; now virtual brainstorming and related virtual methods are used to bring individuals together for problem solving (Nemiro, 2000). In spite of recent criticism on brainstorming that it often does not lead to maximally original solutions (see the review by Rickards \& DeCock, 2012), our findings indicated that the originality of the ideas increased in groups. Recall also that extraversion and social preferences were not related to ideation and did not interact with costs. Hence, the expectation that brainstorming in groups hinders introverts' performance on the generation of original ideas was not supported.

There are practical implications for educational settings as well. Teachers might be able to manipulate the classroom setting such that both group work and original thinking are possible - so group work does not interfere with original thinking and ideation. If handled correctly, group projects should be assigned rather than, or in addition to, individual work even when originality is the goal.

\section{Limitations}

There are several limitations to the research presented here. The three indices of divergent thinking were, for example, highly correlated, which implies that originality may be confounded by fluency (Hocevar, 1979). Still, it would be untenable to focus on fluency or ignore originality. Previous empirical research confirms that fluency and originality, though often highly correlated, are distinct. One demonstration of independence was experimental: Runco (1986b) demonstrated that explicit instructions to be original had negligible impact on the other indices of divergent thinking, while explicit instructions to be flexible did not influence fluency or originality. Another line of support for the distinctiveness of fluency and originality was described by Runco and Albert (1985). They demonstrated that originality has reliable variance even after fluency scores are statistically covaried.

It would certainly be informative to replicate the study of costs using other measures of originality. The findings should also be replicated with other samples of participants and with additional measures of divergent thinking. Only two divergent thinking tasks were used here, and thus the findings do not apply to realistic or figural DT tasks (Runco, 2013). Perhaps most importantly, only social costs were examined herein. Costs are quite varied (Rubenson \& Runco, 1992), and other costs - such as temporal costs - might 
also be informative. Now that a reliable method is available for the measurement of value, several avenues for additional research are available, including those examining the role of ego-strength and the impact of temporal costs. Given the prevalence of the tworequirement definition of creativity and the practical implications for businesses and schools, this additional research is warranted.

\section{REFERENCES}

Albert, R. S. (1975). Toward a behavioral definition of genius. American Psychologist, 30, 140-151.

Anderson, N. H. (1980). Information integration theory in developmental psychology. In F. Wilkening, J. Beden, \& T. Trabasso (Eds.), Information integration by children (pp. 1-45). Hillsdale, NJ: Lawrence Erlbaum Associates, Inc.

Bruner, J. (1962). The conditions of creativity. In J. Bruner (Ed.), On knowing: Essays for the left hand, (pp. 17-30). Cambridge, MA: Harvard University Press.

Cohen, J., \& Cohen, P. (1975). Applied multiple regression/correlation analysis for the behavioral sciences. Hillsdale, NJ: Erlbaum.

Costa, P. T. Jr., \& McCrae, R. R. (1992). Four ways five factors are basic. Personality and Individual Differences, 13, 653-665.

Dennis, A., \& Gallupe, R. B (1993). A history of group support system empirical research: Lessons learned and future directions. In L. M. Jessup \& J. S Valacich (Eds.), Group support systems: New perspectives (pp. 59-77). New York: MacMillan.

Diehl, M., \& Stroebe, W. (1987). Productivity loss in brainstorming groups. Toward the solution of a riddle. Journal of Personality and Social Psychology, 53, 497-509.

Dollinger, S., Burke, P A., \& Gump, N. W. (2007). Creativity and values. Creativity Research Journal, 19, 91-103.

Goncalo, J. A., \& Duguid, M. M. (2012). Follow the crowd in a new direction: When conformity pressure facilitates group creativity (and when it does not). Organizational Behavior and Human Decision Processes, 118, 14-23.

Guilford, J. P. (1967). The nature of human intelligence. New York: McGraw-Hill.

Guilford, J. P. (1968). Creativity, intelligence and their educational implications. San Diego, CA: EDITS/Knapp.

Hocevar, D. (1979). Ideational fluency as a confounding factor in the measurement of originality. Journal of Educational Psychology, 71, 191-196.

Karau, S. J., \& Williams, K. D. (1993). Social loafing: A meta-analytic review and theoretical integration. Journal of Personality and Social Psychology, 65, 681-706. 
Kasof, J., Chen, C., Himsel, A., \& Greenberger, E. (2007). Values and creativity. Creativity Research Journal, 19, 105-122.

Larey, T. S., \& Paulus, P. B. (1999). Group preference and convergent tendencies in small groups: A content analysis of group brainstorming performance. Creativity $R e-$ search Journal, 12, 175-184.

McGrath, J. E. (1984). Groups: Interaction and performance. New York, NY: Prentice Hall. Mueller, J. S., Melwani, S., \& Goncalo, J. A. (2012). The bias against creativity: People people desire yet reject creative ideas. Psychological Science, 23, 13-17.

Nemiro, J. (2002). The creative process in virtual teams. Creativity Research Journal, 14, 69-83.

Osborn, A. F. (1957). Applied imagination: Principles and procedures of creative problemsolving. New York, NY: Charles Scribner's Sons.

Parnes, S. J., \& Meadow, A. (1959). Effects of" brainstorming" instructions on creative problem solving by trained and untrained subjects. Journal of Educational Psychology, 50, 171-176.

Paulus, P. B., \& Dzindolet, M. T. (1993). Social influence processes in group brainstorming. Journal of Personality and Social Psychology, 64, 575-586.

Plucker, J. A., Runco, M. A. \& Lim, W. (2006). Predicting ideational behavior from divergent thinking and discretionary time on task. Creativity Research Journal, 18, 55-63.

Rickards, T., \& DeCock, C. (2012). Understanding organizational creativity: Toward a multiparadigmatic approach. In M. A. Runco (Ed.), Creativity Research Handbook (Vol. 2, pp. 1-32). Cresskill, NJ: Hampton Press.

Rothenberg, A., \& Hausman, C. (1976). The creativity question. Durham, NC: Duke University Press.

Rubenson, D. L., \& Runco, M. A. (1992). The psychoeconomic approach to creativity. New Ideas in Psychology, 10, 131-147.

Runco, M. A. (1985). Reliability and convergent validity of ideational flexibility as a function of academic achievement. Perceptual and Motor Skills, 61, 1075-1081.

Runco, M. A. (1986a). Flexibility and originality in children's divergent thinking. Journal of Psychology, 120, 345-352.

Runco, M. A. (1986b). Maximal performance on divergent thinking tests by gifted, talented, and nongifted children. Psychology in the Schools, 23, 308-315.

Runco, M. A. (1988). Creativity research: Originality, utility, and integration. Creativity $R e-$ search Journal, 1, 1-7.

Runco, M. A. (1991). Divergent thinking. Norwood, NJ: Ablex.

Runco, M. A. (1996). Personal creativity: Definition and developmental issues. New Directions for Child Development, 72, 3-30.

Runco, M. A. (1999). Divergent thinking. In M. A. Runco \& S. Pritzker (Eds.), Encyclope- 
dia of creativity (pp. 577-582). San Diego, CA: Academic Press.

Runco, M. A. (Ed.) (2013). Divergent thinking and creative potential. Cresskill, NJ: Hampton Press.

Runco, M. A., \& Albert, R. S. (1985). The reliability and validity of ideational originality in the divergent thinking of academically gifted and nongifted children. Educational and Psychological Measurement, 45, 483-501.

Runco, M. A., \& Charles, R. E. (1993). Judgments of originality and appropriateness as predictors of creativity. Personality and Individual Differences, 15, 537-546.

Runco, M. A., \& Jaeger, G. (2012). The standard definition of creativity. Creativity Research Journal, 24, 92-96.

Runco, M. A., \& Mraz, W. (1992). Scoring divergent thinking tests using total ideational output and a creativity index. Educational and Psychological Measurement, 52, 213-221.

Rushton, P., Murray, H. G., \& Paunonen, S. V. (1983). Personality, research creativity, and teaching effectiveness. In R. S. Albert (Ed.), Genius and eminence (pp. 281-301). Oxford: Pergamon Press.

Simonton, D. K. (2012). Taking the U.S. Patent Office criteria seriously: A quantitative three-criterion creativity definition and its implications. Creativity Research Journal, 24, 97-106.

Sosik, J. J., Kahai, S. S., \& Avolio, B. J. (1998). Transformational leadership and dimensions of creativity: Motivating idea generation in computer-mediated groups. Creativity Research Journal, 11, 111-121.

Sternberg, R. J. (1995). Defying the crowd: Cultivating creativity in a culture of conformity. New York: Free Press.

Wallach, M. A., \& Kogan, N. (1965). Modes of thinking in young children: A study of the creativity-intelligence distinction. New York: Holt, Reinhart, \& Winston.

Corresponding author at: Mark A. Runco, 325J Aderhold Hall, University of Georgia, 30602, Athens, GA.

E-mail: runco@uga.edu

CCopyright by Faculty of Pedagogy and Psychology, University of Bialystok, 20 Swierkowa St., 15-328 Bialystok, Poland tel. +48857457283 